\title{
Psychiatric comorbidity and quality of life in patients undergoing hemodialysis
}

\author{
Ayman Abdulfattah Elhadad ${ }^{1}$, Afaf Zein El Abedin Ragab ${ }^{1}$ and Salma Abdelsamed Abdelsamed Atia ${ }^{2 *}$
}

\begin{abstract}
Background: Hemodialysis has been shown to have an adverse impact on the emotional status of patients with end-stage renal disease (ESRD). Common associated psychological problems include depression, anxiety, fatigue, decreased quality of life, and an increased risk for suicide. This cross-sectional study aims to psychiatric assessment of ESRD patients on dialysis and patients' quality of life (QOL). One hundred and seventeen patients with end-stage renal disease undergoing hemodialysis aged from 26 years to 77 years were enrolled from the Dialysis Unit at Shebin El Kom Teaching Hospital and Menoufia University Hospital and were approved by the local medical ethical committee. Cases were selected during the study period from October 2018 till May 2019. A semi-structured interview, clinical psychiatric assessment, psychometric test measuring psychiatric disorders, and psychometric test measuring QOL were measured.

Results: A reduction in scores of all domains of QOL was observed in ESRD patients with depression compared with patients without depression. There was a statistically significant correlation between $\mathrm{QOL}$ and presence of clinical illness either diabetes or hypertension among ESRD patients $(P<0.05)$. It was found that there was a reduction in all domains of QOL in patients with clinical illness compared with patients without.

Conclusions: Incidence of psychiatric illness among end-stage renal disease patients on hemodialysis is high. The most prevalent psychiatric disorders among these patients are depression and anxiety disorders. Poor quality of life (QOL) was also observed in ESRD patients.
\end{abstract}

Keywords: Hemodialysis, Psychiatric comorbidity, Quality of life

\section{Background}

Chronic renal disease (CRD) is characterized by varying degrees of deterioration of the functional capacity of the renals. The last stage of this illness is end-stage renal disease (ESRD), at which point hemodialysis (HD) treatment is necessary for patient survival [1].

This therapeutic option imposes a considerable burden on both patients and their families, which can be also worsened by several other complications [2]. For CRF patients on HD, the hemodialysis becomes a central element of their lives, imposing major time restrictions due to the rigid scheduling of dialysis sessions. In addition, restrictions on diet and the pathology itself can affect the patient's mental state and reduce the quality of life (QOL). These problems are linked to increased morbidity and mortality among these patients [3]. The beginning of dialysis treatment

\footnotetext{
* Correspondence: drsalmaa666@gmail.com

${ }^{2}$ Shebin El Kom Teaching Hospital, Menoufia, Egypt

Full list of author information is available at the end of the article
}

causes subtle changes in the life of CRD patients, mainly in the physical and social spheres. For this reason, individuals diagnosed with CRD usually develop neuropsychiatric complications [4]. Hemodialysis has been shown to have an adverse impact on the emotional status of patients with end-stage renal disease (ESRD). Common associated psychological problems include depression, anxiety, fatigue, decreased quality of life, and increased risk for suicide [5]. Many studies point out that compared with the general population, the quality of life is lower in patients with ESRD probably due to factors such as the limitations caused by the disease and requirements of dialysis treatment. In the process leading to ESRD, different and progressive metabolic, hormonal, and emotional irregularities encountered by the patients increase their burden [6]. Both medical and psychosocial factors can affect the survival of ESRD patients treated with HD. Possibly one of the most important psychosocial factors is the presence of psychiatric disorders, which are associated with poor prognosis and high 
mortality in this population [7]. The aim of this study was to assess psychiatric comorbidity with ESRD patients on dialysis and patients' quality of life (QOL).

\section{Methods}

A descriptive cross-sectional study was conducted on 117 patients with end-stage renal disease undergoing hemodialysis aged from 26 years to 77 years who were enrolled from the Dialysis Unit at both Shebin El Kom Teaching Hospital and Faculty of Medicine Menoufia University Hospital during the study period from October 2018 till May 2019.

\section{Ethical consideration}

The study was approved by the ethical committee of Menoufia Faculty of Medicine, and a written informed consent obtained from all patients before the study was commenced.

\section{Inclusion criteria}

This includes those aged between 20 and 80 years, both sexes, and those with end-stage renal disease (ESRD) patients on maintenance hemodialysis for more than 3 months who were stable enough to complete the assessment (alert, conscious, oriented to place, time, and persons).

\section{Exclusion criteria}

This includes patients with any psychiatric illness before renal affection, patients with any other physical illness other than diabetes mellitus (DM) and hypertension, patients with acute infection, patient exposed to hospitalization, major surgeries, and recent trauma less than 6 months, and patients known to have malignancy.

In the present study, all patients were subjected to the following:

Psychiatric assessment using: Full psychiatric history and examination according to Diagnostic and Statistical Manual of Mental Disorders-fourth edition (DSM-IV).

Psychometric test measuring psychiatric disorders (Structured Clinical Interview for DSM Disorders) (SCIDI) First et al. [8]: The SCID1 is a semi structured interview used for diagnosing the major Axis I DSM-IV disorders. It uses a decision tree approach, guiding the clinician through an interview testing diagnostic hypotheses. The Arabic version of the SCID-I used in this study was translated and validated through previous research conducted by El Missiry et al. [9], in the Institute of Psychiatry, Ain Shams University.

Psychometric test measuring QOL: Using Ferrans and Powers Quality of life index for Dialysis version-III [10] translated into Arabic by Halabi [11]. The instrument consists of two parts. The first part measures satisfaction with various aspects of life, and the second measures the importance of the same aspects. Importance ratings are used to weigh the satisfaction responses. Therefore, the scores reflect the respondents' satisfaction with the aspects of life as they value. Total scores may be classified in three levels: desirable (score: 20-30), relatively desirable (score: 10-19), and unfavorable (score: 0-9).

Statistical analysis: Results were tabulated and statistically analyzed by using a personal computer using MICROSOFT EXCEL 2016 and SPSS v. 21 (SPSS Inc., Chicago, IL, USA). Statistical analysis was done using descriptive, e.g., percentage (\%), mean, and standard deviation. Analytical includes chi-squared $\left(\chi^{2}\right)$ and $t$ test. A value of P less than 0.05 was considered statistically significant.

\section{Results}

A total of 117 patients, with mean age $55.8 \pm 11.78$, were included, 65 of them were males (55.6\%) and $52(44.4 \%)$ were females. Results showed that $47 \%$ of the ESRD patients started dialysis $>5$ years ago, $48.7 \%$ stared dialysis $1-5$ years ago and only $4.3 \%$ of them started dialysis < 1 year ago. $26.5 \%$ of patients have diabetes mellitus, $19.7 \%$ have hypertension, and $8.5 \%$ have diabetes and hypertension, while 45.3\% have not medical comorbidities. Also, there was a high prevalence of psychiatric comorbidities among patients undergoing hemodialysis, as more than two third (75.21\%) of dialysis patients suffered from psychiatric illness and only $24.75 \%$ of them did not have any psychiatric illness. More than half $(56.4 \%)$ of dialysis patients have depression, and $51.3 \%$ of them have anxiety disorders, while 7.7\% of patients have panic attacks, (Table 1, Figs. 1 and 2). We found no other psychiatric comorbidities.

The current study shows that depression was more observed in patients having more than three children (70.8\%) and primary education $(77.8 \%)$ and in patients who stopped working after dialysis $(73.1 \%)$, while there was no statistically significant correlation between age, sex, or marital status and presence of depression in ESRD patients $(p>0.05)$. Regarding the presence of anxiety in ESRD patients, anxiety was more observed in males $(67.7 \%)$ than females $(30.8 \%)$ and more observed in married patients $(60.8 \%)$ than in single, divorced, or widowed ones. Also, anxiety was more observed in

Table 1 Duration of dialysis and presence of medical and psychiatric comorbidities among the ESRD patients

\begin{tabular}{lllll}
\hline Variable & & No. $(N=117)$ & $\%$ & \\
Onset of dialysis & $<1$ y & 5 & 4.3 & \\
& $1-5 y$ & 57 & 48.7 & \\
& $>5 y$ & 55 & 47 & \\
Psychiatric comorbidities & Yes & & No & \\
& No. & $\%$ & No. & $\%$ \\
- Depression & 66 & 56.4 & 51 & 43.6 \\
- Panic & 9 & 7.7 & 108 & 92.3 \\
- Anxiety & 60 & 51.3 & 57 & 48.7 \\
\hline
\end{tabular}

ESRD end-stage renal diseases 


\section{Medical comorbidities}

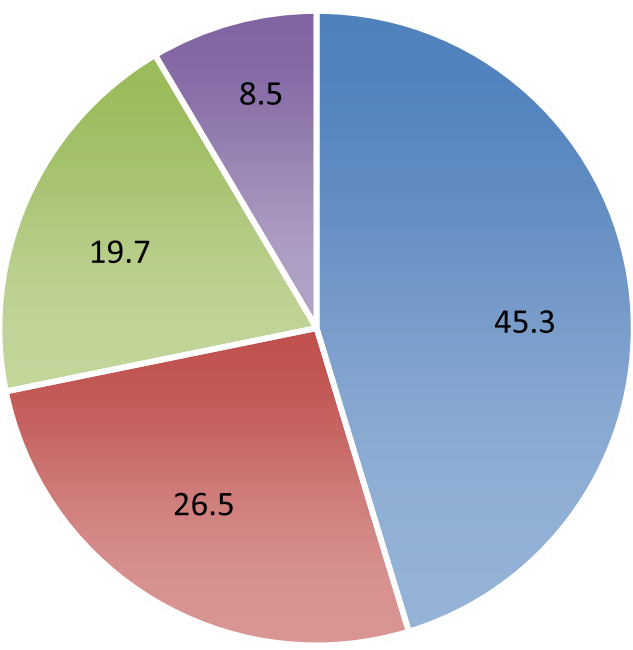

No

Diabetes

Hypertension

- Diabetes and hypertension

Fig. 1 Presence of medical comorbidities among the ESRD patients

patients having $>3$ children (75\%), and more observed in primary educated (55.6\%) and those who had not working (45\%), (Table 2).

Regarding the relationship between the sociodemographic data and total QOL, there was a highly statistically significant correlation between total QOL with age, marital status, education level, and occupation $(p<0.001)$, the highest scores were more observed in single patients (18.44429), university graduated patients (16.55033), and working patients (15.5314). The lowest scores were recorded in widowed (7.74900), illiterate (10.56017), and those who had not working after dialysis (11.0633). On the other hand, there was no statistically significant correlation between age and total QOL $(p=0.422)$ (Table 3).

Additionally, the current study shows that there was a highly statistically significant correlation between QOL score and presence of depression in ESRD patients. $(p<0.001)$. It shows reduction in scores of all domains of QOL in ESRD

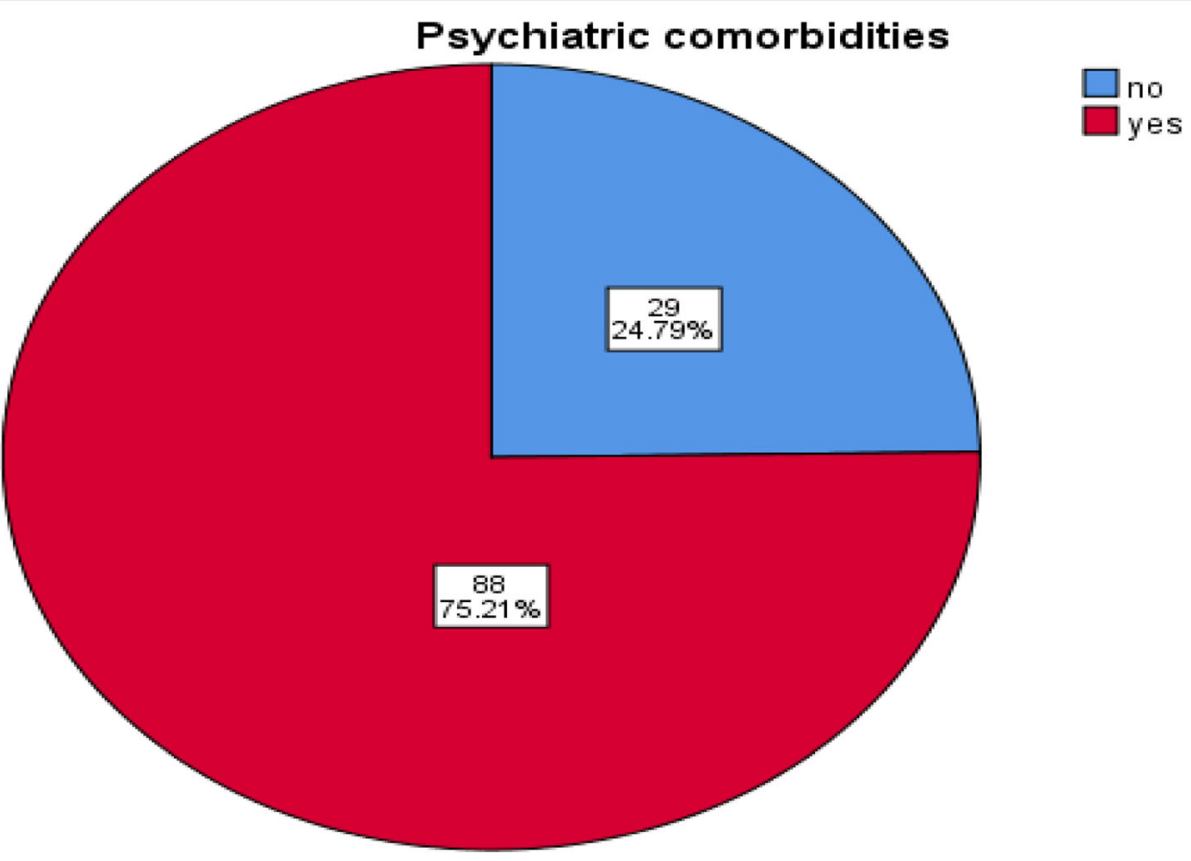

Fig. 2 Presence of psychiatric comorbidities among the ESRD patients 
Table 2 Relation between sociodemographic data and psychiatric comorbidity in end stage renal diseases patients

\begin{tabular}{|c|c|c|c|c|c|c|c|}
\hline \multirow[t]{2}{*}{ Variable } & & \multicolumn{2}{|c|}{ Depression $(N=66)$} & \multicolumn{2}{|c|}{ Absent depression $(N=51)$} & \multirow[t]{2}{*}{ Sig. test } & \multirow[t]{2}{*}{$P$ value } \\
\hline & & No. & $\%$ & No. & $\%$ & & \\
\hline Age & Mean (SD) & \multicolumn{2}{|c|}{$56.98 \pm 10.828$} & \multicolumn{2}{|c|}{$54.29 \pm 12.861$} & $t=0.895$ & 0.654 \\
\hline \multirow[t]{2}{*}{ Sex } & Male $(n=65)$ & 34 & $52.3 \%$ & 31 & $47.7 \%$ & \multirow[t]{2}{*}{$X^{2}=0.352$} & \multirow[t]{2}{*}{0.208} \\
\hline & Female $(n=52)$ & 32 & $61.5 \%$ & 20 & $38.5 \%$ & & \\
\hline \multirow[t]{4}{*}{ Marital status } & Single & 2 & $28.6 \%$ & 5 & $71.4 \%$ & \multirow[t]{4}{*}{$X^{2}=4.580$} & \multirow[t]{4}{*}{0.205} \\
\hline & Married & 55 & $56.7 \%$ & 42 & $43.3 \%$ & & \\
\hline & Divorced after dialysis & 3 & $100 \%$ & 0 & $0 \%$ & & \\
\hline & Widow & 6 & $60 \%$ & 4 & $40 \%$ & & \\
\hline \multirow[t]{3}{*}{ Number of children } & Non & 9 & $60 \%$ & 6 & $40 \%$ & \multirow[t]{3}{*}{$x^{2}=8.332$} & \multirow[t]{3}{*}{$0.016^{*}$} \\
\hline & $1-3$ & 23 & $42.6 \%$ & 31 & $57.4 \%$ & & \\
\hline & $>3$ & 34 & $70.8 \%$ & 14 & $29.2 \%$ & & \\
\hline \multirow[t]{4}{*}{ Education } & Illiterate & 35 & $59.3 \%$ & 24 & $40.7 \%$ & \multirow[t]{4}{*}{$x^{2}=8.176$} & \multirow[t]{4}{*}{$0.043^{*}$} \\
\hline & Primary educated & 7 & $77.8 \%$ & 2 & $22.2 \%$ & & \\
\hline & High school & 19 & $61.3 \%$ & 12 & $38.7 \%$ & & \\
\hline & University & 5 & $27.8 \%$ & 13 & $72.2 \%$ & & \\
\hline \multirow[t]{5}{*}{ Occupation } & Working & 12 & $38.7 \%$ & 19 & $61.3 \%$ & \multirow[t]{3}{*}{$x^{2}=6.977$} & \multirow[t]{3}{*}{$0.031^{*}$} \\
\hline & Not working & 35 & $58.3 \%$ & 25 & $41.7 \%$ & & \\
\hline & Stopped working after dialysis & 19 & $73.1 \%$ & 7 & $26.9 \%$ & & \\
\hline & & \multicolumn{2}{|c|}{ Anxiety $(N=60)$} & \multicolumn{2}{|c|}{ Absent anxiety $(N=57)$} & \multirow[t]{2}{*}{ Sig. test } & \multirow[t]{2}{*}{$P$ value } \\
\hline & & No. & $\%$ & No. & $\%$ & & \\
\hline Age & Mean (SD) & 57.45 & & 54.0 & & 1.759 & $0.016^{*}$ \\
\hline Sex & Male & 44 & $67.7 \%$ & 21 & $32.3 \%$ & 15.764 & $<0.001^{* *}$ \\
\hline & Female & 16 & $30.8 \%$ & 36 & $69.2 \%$ & & \\
\hline Marital status & Single & 0 & $0 \%$ & 7 & $100 \%$ & $x^{2}=20.883$ & $<0.001^{* *}$ \\
\hline & Married & 59 & $60.8 \%$ & 38 & $39.2 \%$ & & \\
\hline & Divorced after dialysis & 0 & $0 \%$ & 3 & $100 \%$ & & \\
\hline & Widow & 1 & $10 \%$ & 9 & $90 \%$ & & \\
\hline Number of children & Non & 3 & $20 \%$ & 12 & $80 \%$ & $x^{2}=20.003$ & $<0.001^{* *}$ \\
\hline & $1-3$ & 21 & $38.9 \%$ & 33 & $61.1 \%$ & & \\
\hline & $>3$ & 36 & $75 \%$ & 12 & $25 \%$ & & \\
\hline Education & Illiterate & 32 & $54.2 \%$ & 27 & $45.8 \%$ & $x^{2}=2.75$ & 0.432 \\
\hline & Primary educated & 5 & $55.6 \%$ & 4 & $44.4 \%$ & & \\
\hline & High school & 17 & $54.8 \%$ & 14 & $45.2 \%$ & & \\
\hline & University & 6 & $33.3 \%$ & 12 & $66.7 \%$ & & \\
\hline Occupation & Working & 12 & $38.7 \%$ & 19 & $61.3 \%$ & $X^{2}=11.958$ & $0.003^{* *}$ \\
\hline & Not working & 27 & $45 \%$ & 33 & $55 \%$ & & \\
\hline & Stopped working after dialysis & 21 & $80.8 \%$ & 5 & $19.2 \%$ & & \\
\hline
\end{tabular}

$S D$ standard deviation, $X^{2}$ chi square

The symbol * means significant value

The symbol ** means highly significant value

patients with depression compared with patients without depression. There was no statistically significant correlation between anxiety and health, socioeconomic, psychological and family domains, and total QOL scores $(p>0.05)$. Also, there was no statistically significant correlation between panic and health, socioeconomic, psychological and family domains and total QOL scores $(p>0.05)$ (Table 4$)$.

Concerning, correlation between total QOL with medical comorbidities and duration of dialysis, there was a statistically significant correlation between QOL and 
Table 3 Relation between sociodemographic data and QOL assessed by Ferrans and Powers Quality of life scale among ESRD patients

\begin{tabular}{|c|c|c|c|c|}
\hline \multirow[t]{2}{*}{ Sociodemographic data } & \multicolumn{4}{|c|}{ Total quality life (QOL) } \\
\hline & $\overline{M e a n}$ & SD & Sig. test & $P$ value \\
\hline Age & 12.47364 & 3.886928 & -2.646 & $<0.001^{* *}$ \\
\hline \multicolumn{5}{|l|}{ Sex } \\
\hline Male & 12.7329 & 3.795743 & 0.643 & 0.422 \\
\hline Female & 12.1495 & 4.011331 & & \\
\hline \multicolumn{5}{|l|}{ Marital status } \\
\hline Single & 18.44429 & 1.532360 & 13.927 & $<0.001^{* *}$ \\
\hline Married & 12.52625 & 3.514332 & & \\
\hline Divorced after dialysis & 12.59000 & 4.866939 & & \\
\hline Widow & 7.74900 & 1.896391 & & \\
\hline \multicolumn{5}{|l|}{ Educational level } \\
\hline Illiterate & 10.56017 & 3.131876 & 21.778 & $<0.001^{* *}$ \\
\hline Primary & 10.71111 & 2.594000 & & \\
\hline High school & 14.26000 & 3.598981 & & \\
\hline University & 16.55033 & 2.415480 & & \\
\hline \multicolumn{5}{|l|}{ Occupational state } \\
\hline Working & 15.5314 & 3.068196 & 17.584 & $<0.001^{* *}$ \\
\hline Not working & 11.0633 & 3.633154 & & \\
\hline Stopped working after dialysis & 12.0823 & 3.335666 & & \\
\hline
\end{tabular}

ESRD end-stage renal diseases, $t$ Student $t$ test, SD standard deviation

The symbol ** means significant value

presence of clinical illness either diabetes or hypertension among ESRD patients $(P<0.05)$. It was found that there was a reduction in all domains of QOL in patients with clinical illness compared with patients without. There was no statistically significant correlation between duration of dialysis and health, social, psychological and family domains, and total QOL scores $(p>0.05)$ (Table 5).

\section{Discussion}

Our study showed that $75.2 \%$ of them suffered from psychiatric illness $56.4 \%$ of them suffered from depression, while
$51.3 \%$ of them suffered from generalized anxiety disorders, $21.4 \%$ had suicidal ideations, and $7.7 \%$ suffered from panic attacks. No symptoms of mania, hypomania, and dysthymia were detected. Also, no symptoms of OCD, PTSD, social phobia, specific phobias, or somatization disorder were detected after assessment using SCIDI scale. These findings agreed with the study done by Kober et al. [12], which was done on 100 patients 50 of them were cases of ESRD and the other 50 were control group, using HAM scale (Hamilton Rating scale) for anxiety and BDI (Beck Depression Inventory) for depression as he found that the

Table 4 Relation between QOL among patients with and without depression, anxiety, and suicidal ideations

\begin{tabular}{|c|c|c|c|c|}
\hline \multirow[t]{2}{*}{ Variable } & Depression & Absent depression & \multirow[t]{2}{*}{ Sig. test } & \multirow[t]{2}{*}{$P$ value } \\
\hline & Mean SD & Mean SD & & \\
\hline QOL total & 11.15348 (3.503672) & 14.18208 (3.716849) & 20.385 & $0.000^{* *}$ \\
\hline \multirow[t]{2}{*}{ Variable } & Anxiety & Absent anxiety & \multirow[t]{2}{*}{ Sig. test } & \multirow[t]{2}{*}{$P$ value } \\
\hline & Mean SD & Mean SD & & \\
\hline QOL total & 12.111672 .785497 & 12.854674 .778364 & 1.069 & 0.303 \\
\hline \multirow[t]{2}{*}{ Variable } & Panic & No panic & \multirow[t]{2}{*}{ Sig. test } & \multirow[t]{2}{*}{$P$ value } \\
\hline & Mean SD & Mean SD & & \\
\hline QOL total & 11.477781 .780083 & 12.556634 .006459 & 0.638 & 0.426 \\
\hline
\end{tabular}

QOL: desirable (score: 20-30), relatively desirable (score: 10-19), and unfavorable (score: 0-9)

ESRD end-stage renal diseases, SD standard deviation, $t$ Student $t$ test

The symbol ${ }^{* *}$ means significant value 
Table 5 Relation between QOL with clinical comorbidities and duration of dialysis and QOL

\begin{tabular}{|c|c|c|c|c|c|c|}
\hline \multirow[t]{2}{*}{ Variable } & Non & Diabetes & Hypertension & Diabetes and hypertension & Sig. $t$ test & $P$ value \\
\hline & Mean SD & Mean SD & Mean SD & Mean SD & & \\
\hline \multirow[t]{2}{*}{ Health } & 14.4528 & 10.3203 & 10.2048 & 11.0320 & 10.686 & $0.000^{* *}$ \\
\hline & 4.31670 & 3.77421 & 3.20621 & 3.02234 & & \\
\hline \multirow[t]{2}{*}{ Social } & 13.6523 & 10.5284 & 10.8043 & 11.0080 & 6.238 & $0.001^{* *}$ \\
\hline & 4.04040 & 3.76897 & 2.97001 & 2.72714 & & \\
\hline \multirow[t]{2}{*}{ Psychological } & 13.6925 & 10.7258 & 12.0843 & 11.9140 & 3.720 & $0.014^{* *}$ \\
\hline & 4.07448 & 4.03543 & 3.95834 & 3.73034 & & \\
\hline \multirow[t]{2}{*}{ Family } & 15.1721 & 11.9155 & 12.7278 & 13.2040 & 4.363 & $0.006^{* *}$ \\
\hline & 4.60154 & 4.36019 & 3.78274 & 2.68295 & & \\
\hline \multirow[t]{2}{*}{ QOL total } & 14.22785 & 10.71161 & 11.19087 & 11.58900 & 7.937 & $0.000^{* *}$ \\
\hline & 3.868080 & 3.651926 & 3.046260 & 2.692836 & & \\
\hline \multirow[t]{2}{*}{ Variable } & Less than 1 year & From 1 to 5 years & More than 5 years & & Sig. test & $P$ value \\
\hline & Mean SD & Mean SD & Mean SD & & & \\
\hline \multirow[t]{2}{*}{ Health } & 14.3940 & 11.8782 & 12.3987 & & 0.847 & 0.431 \\
\hline & 5.73691 & 4.24813 & 4.33331 & & & \\
\hline \multirow[t]{2}{*}{ Social } & 14.4460 & 11.9575 & 11.9040 & & 0.983 & 0.377 \\
\hline & 5.33806 & 3.81916 & 3.91878 & & & \\
\hline \multirow[t]{2}{*}{ Psychological } & 12.5580 & 12.6172 & 12.2420 & & 0.115 & 0.892 \\
\hline & 4.14740 & 4.18959 & 4.18528 & & & \\
\hline \multirow[t]{2}{*}{ Family } & 17.2820 & 13.7105 & 13.2795 & & 1.897 & 0.155 \\
\hline & 5.27950 & 4.24387 & 4.50264 & & & \\
\hline \multirow[t]{2}{*}{ QOL total } & 14.45320 & 12.35842 & 12.41309 & & 0.676 & 0.510 \\
\hline & 4.870916 & 3.780593 & 3.936289 & & & \\
\hline
\end{tabular}

QOL: desirable (score: 20-30), relatively desirable (score: 10-19), and unfavorable (score: 0-9), SD standard deviation, $t$ Student $t$ test The symbol ** means significant value

prevalence of psychiatric illness among them was $44 \%, 40 \%$ of patients suffered from depression, while the percentage of patients suffering from anxiety disorders were $42 \%$. These findings agree with Garcia et al. [13], who found that (68.1\%) of them had score equal to or more than 7 , which suggested depression. Psychiatric illness in end-stage renal disease patients could be attributed to multiple stressors they face such as financial problems, difficulty in holding a job, waning a sexual desire and impotence, fear of dying, fluid limitation, food limitation, itching, fatigue, limitations on time, risk of unemployment, transportation difficulties, loss of bodily function, length of dialysis treatment, and limitation of physical activities. Younger patients worry about marriage, having children, and the burden that they bring to their family [14].

Our study showed that there was a significant correlation between age of the patient and anxiety as anxiety symptoms increases with advancement of age. These findings agree with those of Bossola et al. [15], whose study was carried out using 80 hemodialysis patients assessed for depression by BDI (Beck Depression Inventory) and for anxiety using Hamilton Anxiety Rating
Scale (HARS) which found that HARS correlates significantly with age, but disagree with study done by Stasiak et al. [16], who found that age of the patients had negative correlation with anxiety. These also disagreed with those of Kumar et al. [17], who found that there was no relationship between age group and anxiety. Anxiety in older patients observed in our study may be attributed to the higher prevalence of somatic symptoms and the more fears of death among old patients.

Concerning depression and age, our findings come in agreement with Patel et al.'s [18] study which was carried out on 150 patients and revealed that there was no significant correlation between age and presence of depression, while it disagreed with a study done by Keskin and Engin [19], which was carried out on 92 dialysis patients using BDI scale and showed that depression among dialysis patients increases with age.

Regarding anxiety, our study showed that anxiety is more observed in males and married patients. This comes in agreement with a study done by Kober et al. [12], who found that male patients had $65 \%$ of psychiatric disorders including anxiety. Also, these results disagreed with those 
of Theofilou's [20] study which was done on 144 ESRD patients, using State-Trait Anxiety Inventory (STAI) and found that females reported more anxiety traits than males.

Our results also showed that anxiety was more observed among patients stopped working, while there was no significant relationship between educational level and presence of anxiety. These results come in agreement with the study done by Kumar et al. [17] on 150 hemodialysis patients and found a significant relationship between anxiety and occupational state while there was no significant relationship between it and educational level. Our results could be attributed to the fact that married male patients undergoing hemodialysis are subjected to more stress caused by work, unemployment, living situations, and sexual dysfunction [21].

Our study showed that depression was more observed in low educated patients and less in university graduated. Also, depression was more observed in unemployed patients either not working before dialysis or stopped working after dialysis. These results come in agreement with a study done by Aggarwal et al [22], which was a cross-sectional study done on 200 patients of CKD stage III to stage $\mathrm{V}$ with dialysis and revealed that depression was significantly correlated to unemployment and low education. On the other hand, our findings disagree with those of Kumar et al. [17], who showed that there was no significant relationship between depression and educational level or occupational state.

Our study showed that there was no significant correlation between sex and quality of life QOL. These findings were similar to those of the study done by Pagels et al. [23] which was done on 535 patients assessed for HRQoL through SF-36 and found that there was no association between HRQoL and gender but were in contradiction with the study done by Gentile et al. [24], who found that females had lower SF-36 scores, and the study done by AL-Jumaih et al. [25], who found that physical component, mental health component, and renal disease component of Kidney Disease Quality of Life (KD-QOL) scale were higher in males than females.

Our study showed that total QOL scores in single patients were better than married, and married were better than widowed and divorced. These findings were in agreement with the study done by Sabbah et al. [26], who revealed that unmarried patients have better quality of life than married but were in contrast with the study done Sathvik et al. [27], who showed that there was no association between marital status and quality of life. These findings could be justified as single patients have less responsibilities towards their families, while married, divorced, and widowed ones may have more duties they cannot met which represent more burden affecting their QOL.

Our study showed that all domains of QOL were significantly affected by educational level and low-educated patients either illiterate or primary educated had lower scores, while higher scores were observed among universityeducated patients. These findings are similar to studies by Sabbah et al. [26] and Pakpour et al. [28] that found that increased education raised the QOL. It seems that highly educated patients may have advantages in monitoring and evaluating different aspects of their external world. Also, more educated patients seem to be better equipped to create for themselves a more satisfactory environment, with better health services and finances [20]. Moreover, higher education has a role in raising the awareness of the disease and increases the ability to cope with chronic diseases [27].

The current study revealed that lower QOL scores were observed in unemployed patients either stopped working after dialysis or did not work before dialysis than employed patients. These agree with (Sathvike et al. [27], Kalender et al. [29], as they revealed that working patients have better QOL than not working ones. This could be explained that daily activity and work capacity may help to improve quality of life [27]. Also, holding down a job has a positive influence on the individual that has a role in society and it contributes to improve self-esteem, which is considered to be an important aspect of quality of life [30].

\section{Conclusion}

Incidence of psychiatric illness among end-stage renal disease patients on hemodialysis is high. The most prevalent psychiatric disorders among these patients are depression and anxiety disorders. There was a statistically significant correlation between age and educational level among ESRD patients. Poor quality of life (QOL) was also observed in ESRD patients. Training programs should be initiated towards early detection of psychiatric illness among ESRD patients and early initiation of treatment.

\section{Limitations}

This study is a cross-sectional study, which eliminates the causal efficacy of all data. The sample size of the study was small, as inclusion criteria were restricted to the patients who accepted the participation in the study which may limit the generalizability of the study. However, as the sample has been recruited from two of the largest dialysis centers that serve the Menoufia governorate, this might help to some extent in randomization and variability of the selected sample.

\section{Abbreviations}

BDI: Beck Depression Inventory; CRD: Chronic renal disease; DM: Diabetes mellitus; DSM-IV: Diagnostic and Statistical Manual of Mental Disorders—fourth edition; ESRD: End-stage renal disease; HAM: Hamilton Rating scale; HARS: Hamilton Anxiety Rating Scale; HD: Hemodialysis; KDQOL: Kidney Disease Quality of Life; OCD: Obsessive-compulsive disorder; PTSD: Post-traumatic stress disorder; QOL: Quality of life; SCIDI: Structured Clinical Interview for DSM-IV Axis I Disorders; SPSS: Statistical Package for the Social Sciences; STAl: State-Trait Anxiety Inventory 


\section{Acknowledgements}

We are thankful to the ESDR patients shore my study and to my colleague in renal dialysis department and to my supervisors.

\section{Authors' contributions}

AAE analyzed and interpreted the patient data. AZER and SASASA performed the psychiatric examination and psychometric tests of the patients and were major contributors in writing the manuscript. All authors read, editing, revision, and approved the final manuscript.

\section{Funding}

No funding from authority or company.

\section{Availability of data and materials}

All data generated or analyzed during this study are included in this published article.

\section{Ethics approval and consent to participate}

The study was approved by the Ethics Committee of the Shebin El Kom Teaching Hospital and Menoufia University Hospital. Unfortunately, due to technical issues in our institutional IT system, our ethical committee reference number cannot be retrieved at the moment. However, we would be happy to supply a signed letter from our head of hospital explaining that this research has been previously approved. A written informed consent was taken from participants after discussing the aim and procedures of the study. Participation was totally free and voluntary and did not imply a direct benefit for them. Moreover, they were guaranteed the right to refuse or withdraw from the study at any point without justification or consequences on them or their treated relatives. They were informed that the results could be used for scientific publication, but their identities would be absolutely confidential.

\section{Consent for publication}

Not applicable.

\section{Competing interests}

The authors declare that they have no competing interests.

\section{Author details}

'Department of psychiatry, Faculty of Medicine, Menoufia University, Menoufia, Egypt. ${ }^{2}$ Shebin El Kom Teaching Hospital, Menoufia, Egypt.

Received: 9 December 2019 Accepted: 26 January 2020

Published online: 07 April 2020

\section{References}

1. White SL, Cass A, Atkins RC, Chadban S (2005) Chronic kidney disease in the general population. Adv Chronic Kidney Dis 12(1):5-13

2. D'Onofrio G, Simeoni M, Rizza P, Caroleo M, Capria M, Mazzitello G, Sacco T, Mazzuca E, Panzino MT, Cerantonio A, Segura-Garcia C (2017) Quality of life, clinical outcome, personality and coping in chronic hemodialysis patients. Ren Fail 39(1):45-53

3. Camacho-Alonso F, Cánovas-García C, Martínez-Ortiz C, De la ManoEspinosa T, Ortuño-Celdrán T, Marcello-Godino Jl, Ramos-Sánchez R, Sánchez-Siles M (2018) Oral status, quality of life, and anxiety and depression in hemodialysis patients and the effect of the duration of treatment by dialysis on these variables. Odontology 106(2):194-201

4. Teles F, de Azevedo V, Miranda C, Miranda M, Teixeira M, Flias R (2014) Depression in hemodialysis patients. The role of dialysis shift. Clinics 69(3):198-202

5. Wang LJ, Wu MS, Hsu HJ, Wu IW, Sun CY, Chou CC, Lee CC, Tsai CR, Tsai YC, Chen CK (2012) The relationship between psychological factors, inflammation, and nutrition in patients with chronic renal failure undergoing hemodialysis. Int J Psychiatry Med 44(2):105-118

6. Od B, Aydin E, Keyvan A, Ms Y, Tuna O, Devrimci Ozguven H (2017) Psychiatric comorbidity, sexual dysfunction, and quality of life in patients undergoing hemodialysis: a case-control study. Noro Psikiyatr Ars 54(2):137-142

7. Martiny C, de Oliveira e Silva AC, Neto JP, Nardi AE (2012) Psychiatric disorders in patients with end-stage renal disease. J Renal Care 38(3):131-137

8. First MB, Spitzer RL, Gibbon M, Williams JB (1997) Structured clinical interview for DSM-IV—clinical version (SCID-CV) (user's guide and interview)
9. El Missiry A, Sorour A, Sadek A, Fahy TA, Mawgoud M, Asaad T (2003) Homicide and psychiatric illness: an Egyptian study [MD thesis]. Faculty of Medicine, Ain Shams University, Cairo

10. Ferrans CE, Powers MJ (1992) Psychometric assessment of the quality of life index. Res Nurs Health 15(1):29-38

11. Halabi JO (2006) Psychometric properties of the Arabic version of quality of life index. J Adv Nurs 55(5):604-610

12. Kober L, Rustom R, Wiedmann J, Kappelgaard AM, El Nahas M, FeldtRasmussen B (2010) Cardiovascular effects of growth hormone in adult hemodialysis patients: results from a randomized controlled trial. Nephron Clin Pract 115(3):213-226

13. Garcia TW, Veiga JP, Motta LD, Moura FJ, Casulari LA (2010) Depressed mood and poor quality of life in male patients with chronic renal failure undergoing hemodialysis. Rev Bras Psiquiatr 32(4):369-374

14. Ahmad MM, Al Nazly EK (2015) Hemodialysis: stressors and coping strategies. Psychol Health Med 20(4):477-487

15. Bossola M, Luciani G, Giungi S, Tazza L (2010) Anorexia, fatigue, and plasma interleukin-6 levels in chronic hemodialysis patients. Ren Fail 32(9):1049-1054

16. Stasiak CE, Bazan KS, Kuss RS, Schuinski AF, Baroni G (2014) Prevalence of anxiety and depression and its comorbidities in patients with chronic kidney disease on hemodialysis and peritoneal dialysis. Braz J Nephrol 36(3):325-331

17. Kumar A, Leventhal MR, Freedman EL, Coburn J, Delamarter R (2018) Destructive spondyloarthropathy of the cervical spine in patients with chronic renal failure. Spine 22(5):573-577

18. Patel N, Gross A, Brown L, Gekht GA (2012) Randomized, placebo-controlled study to assess the efficacy of lateral branch neurotomy for chronic sacroiliac joint pain. Pain Med 13(3):383-398

19. Keskin S, Engin A (2011) The evaluation of depression, suicidal ideation and coping strategies in haemodialysis patients with renal failure. J Clin Nurs 20:2721-2732

20. Theofilou P (2011) Quality of life in patients undergoing hemodialysis or peritoneal dialysis treatment. J Clin Med Res 3(3):132-138

21. Rezaei Z, Jalali A, Jalali R, Khaledi-Paveh B (2018) Psychological problems as the major cause of fatigue in clients undergoing hemodialysis: a qualitative study. Int J Nurs Sci 5(3):262-267

22. Aggarwal HK, Jain D, Dabas G, Yadav RK (2017) Prevalence of depression, anxiety and insomnia in chronic renal disease patients and their co-relation with the demographic variables. Prilozi 38(2):35-44

23. Pagels AA, Soderkvist BK, Medin C, Hylander B, Heiwe S (2012) Healthrelated quality of life in different stages of chronic kidney disease and at initiation of dialysis treatment. Health Qual Life Outcomes 10:71

24. Gentile S, Beauger D, Speyer E, Jouve E, Dussol B, Jacquelinet C, Briançon S (2013) Factors associated with health-related quality of life in renal transplant recipients: results of a national survey in France. Health Qual Life Outcomes 11(1):88

25. Al-Jumaih A, Al-Onazi K, Binsalih S, Hejaili F, Al-Sayyari A (2011) A study of quality of life and its determinants among hemodialysis patients using the KDQOL-SF instrument in one center in Saudi Arabia. Arab J Nephrol Transplant 4(3):125-130

26. Sabbah I, Drouby N, Sabbah S, Retel-Rude N, Mercier M (2003) Quality of life in rural and urban populations in Lebanon using SF-36 health survey. Health Qual Life Outcomes 1(1):30

27. Sathvik BS, Parthasarathi G, Narahari MG, Gurudev KC (2008) An assessment of the quality of life in hemodialysis patients using the WHOQOL-BREF questionnaire. Indian J Nephrol 18(4):141

28. Pakpour AH, Saffari M, Yekaninejad MS, Panahi D, Harrison AP, Molsted S (2010) Health-related quality of life in a sample of Iranian patients on hemodialysis. Iran J Kidney Dis 4(1):50

29. Kalender B, Ozdemir AC, Dervisoglu E, Ozdemir O (2007) Quality of life in chronic kidney disease: effects of treatment modality, depression, malnutrition and inflammation. Int J Clin Pract 61(4):569-576

30. Bohlke M, Nunes DL, Marini SS, Kitamura C, Andrade M, Von-Gysel MP (2008) Predictors of quality of life among patients on dialysis in southern Brazil

\section{Publisher's Note}

Springer Nature remains neutral with regard to jurisdictional claims in published maps and institutional affiliations. 